\title{
WELL-BEING AT WORK: A LEVER FOR SUSTAINABLE PERFORMANCE IN WORKPLACE
}

\author{
Mourad AMRANI ${ }^{1,2 *}$, Rachid CHAIB $^{2}$, \\ Azzedine BOUZAOUIT ${ }^{1,3}$, Verzea ION $^{4}$ \\ ${ }^{1}$ University 20 Aout 1955 Skikda, Algeria, e-mail: mouradamrani2000@yahoo.fr \\ ${ }^{2}$ Laboratory of Transportation Engineering and Environment, University of Mentouri Brothers Constantine, \\ Algeria, e-mail: r3chaib@yahoo.fr \\ ${ }^{3}$ University 20 Aout 1955 Skikda, Algeria, e-mail:bouzaouit21@gmail.com \\ ${ }^{4}$ Technological University of Gh. Asachi, Iasi, Romania, e-mail: verzea2000@yahoo.com
}

\begin{abstract}
In a context of increasing pressure on performance, which affects almost all Algerian companies, question effectiveness of a policy of well-being at work depends on its impact on organizational performance: Numerous figures show costs of psychosocial risks, stress, absenteeism, etc. By virtue of the principle that a happy worker would also be a more productive worker, generating benefit for enterprise and a cost-reducing factor, even generating a better productive and commercial performance. Therefore, to reach these expectations, health culture and well-being at work must be part of basic values of actors of work world who are responsible for implementing an integrated preventive approach in all companies. As a result, an appeal is made to all managers and partners to make a joint commitment to effectively and efficiently reduce causes of work accidents and occupational diseases proliferation: company health, it's health in the business. From now on, occupational health capital management and wellbeing of any company is one of its military priorities for its performance. It is part of company strategic objectives and must be taken into account in its daily operation.
\end{abstract}

Keywords: well-being at work, economic performance, health, safe culture

* Corresponding author: mouradamrani2000@yahoo.fr (M. Amrani) 


\section{INTRODUCTION}

If company is first and foremost a place of production, a community with an economic purpose, it can also be a place where stakes of health and well-being of employees are taken care of, place of information, of belief, awareness, prevention, screening to change behaviour and preserve health: a good business, "company health is health in the company" (Chaib 2016). Thus, commitment to work in workplace is at performance source gains and innovation. As a result, and in a contemporary context, companies must manage employees demands of a new "generation", who no longer work "the duty to do" like their parents, but who as citizens, demand more and more "pleasure to do". Keeping as main reality that man is one of major players in generating value for company. So, question of his performance remains an issue for organization. Therefore, a win/win bet is to be met, if company manages to answer, figure 1 . This implies creating common spaces of reflection, relationships, complicity, so that well-being managed by human resources, the performance defended by general management and environment preserved by legislation are found on a common ground. Thus, company must constantly adapt to changes in its environment. However, its ability to meet needs of competitiveness, to innovate, to be dynamic and responsive; in short to be successful is largely based on initiatives that will take or not employees. So, come up with a balanced approach to managing health and workplace safety. The latter is based on a set of prevention services enabling companies and their employees to make diagnosis, implement action plans and measure their return on investment and the impact on performance.

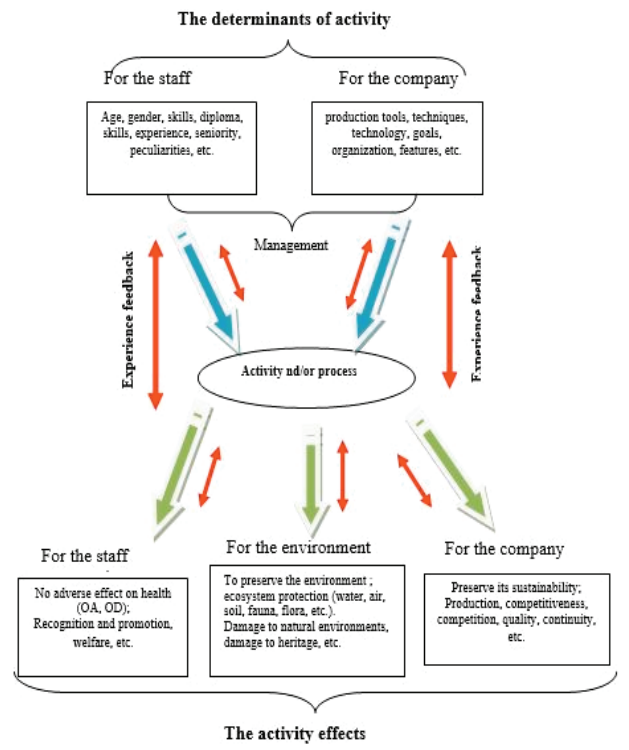

Fig. 1. Principle of sustainable development, win-win (Rachid, Mohamed 2016) 


\section{PROBLEMATIC}

In the past, it is believed that performance generates well-being, which is wrong: it is well-being that generates performance (Millot, Roulleau 2013; Richer 2013; Stiglitz 2002). Thus, it has to choose between prevention of ill-being or promotion of wellbeing? This last point is an additional step to be taken by company which wants an active policy in well-being field, a real stake of brand image and attractiveness, alternative to the bidding wage, the goal being the control of negative impacts of work on life (de l'Europe 2008). Feeling good at work is a strategic issue for all partners in company (Aubry 2005), as well-being concept refers not only to the absence of pathologies or physical and mental illnesses and disabilities, but also to a more general feeling of satisfaction and fulfilment in professional and extra-professional life. This key element of human resources has become an essential element of any thoughtful and global managerial policy, clearly identified as a potential lever for growth and improvement of company's economic results (Médéc 2013). There is a real community of interest between economic efficiency and well-being at work (Phillippe et al. 2014; Lachmann et al. 2010). As a result, well-being must become a priority, along with other company functions (production, maintenance, training plans development, parity promotion, etc.). This forces company to think differently considering that performance notion refers to growth ideas, profitability, profit, in which individual is one of stakeholders in the same way as economy and technology (Achte et al. 2010; Delobbe, De Hoe 2012; DELOCHE 2013). In contrast, well-being notion at work refers to pleasure idea at work, belief, work meaning, valuation, etc., without reference to company economic requirements (Médéc 2014). Our study was conducted in Hamma Bouziane cement plant, Algeria.

\section{METHODOLOGY OF WORK}

In scientific literature, the mental stress sources cited are mainly: monotony, repetitiveness, cadences, a fast pace, attention required, concentration, quantitative or qualitative overload, work based on human relations, responsibilities (workers, goods), conflicting demands, insecurity related to work done, lack of autonomy, inadequate qualification (not enough or too much), relations with hostile or non-helping professional staff. Other possible sources of mental stress: work, sensory loads (noise, light), hours of work, employment: atypical hours, precarious employment "evokes the notion of insecurity, little discussed". The Karasek model (Karasek 1990) seems to be a good way of approaching these measures, in an epidemiological framework - therefore at the level of groups of individuals - mental constraints at work. However, the more recent Sigrist model (Niedhammer et al. 2000; Siegrist et al. 2004) also allows 
a measure of personality profiles (which did not exist in the Karasek model). The latter used in mental constraints study at work and their effects on health. The model and questionnaire validated in English. For the Institute National research in Security (INRS) approach (Robert, Grosjean 2006), it consists of dividing questionnaire into three categories.

In a more specific context, the study investigation is to couple these two methods to the approach proposed by INRS. Through a questionnaire, it is tried to have a global vision on all workers health and to find link between well-being and performance of company.

\section{CASE STUDY: THE WELL-BEING STUDY \\ IN THE HAMMA BOUZIANE CEMENTS SOCIETY}

\subsection{PRESENTATION OF THE COMPANY}

The study was carried out in Cements Company of Hamma Bouziane subsidiary of the group GICA, the latter is an EPE - SPA capital of 2200 million DA; created in 1998. Its portfolio consists of a cement plant located in Hamma Bouziane-Constantine, Algeria with a production capacity of one (01) million tonnes of cement per year and three (03) commercial units established respectively in Constantine, Annaba and Skikda. As it is known, mining industry has very difficult working conditions because of complexity of mineral extraction processes and their transformations. Cement manufacturing process consists of three phases which are: Extraction and grinding of raw materials, Heating and grinding of raw cement, grinding and cement shipping, the following diagrams summarize different stages of this process.

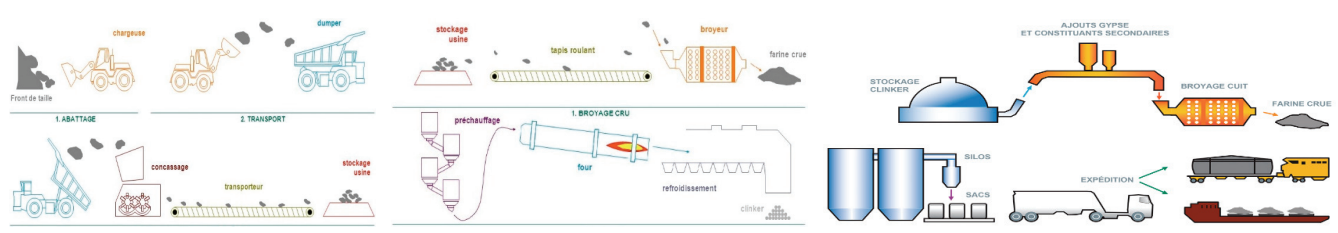

Fig. 2. Cement manufacturing process (document)

Workers who perform their tasks during different stages of cement manufacture undergo daily constraints and pressures for accomplishment of their activities, which is why, from this study, it is tented to arrive providing an explanatory model to understand, what are relationships mechanisms of well-being and performance? 


\subsection{STUDY}

The study is based on a population of one hundred and fifty people, but only one hundred and twenty-nine who responded to the questionnaires distributed. During realization of our work the maximum of services have to be target, in this case administration (service human resources, finances, study office, etc.) and productions services, quality control, maintenance. The questionnaires were distributed to different classes of employees, whether they are important personality or execution personality, to better see who is feeling well and who is feeling bad. When carrying out this work, interview techniques is used, to facilitate questionnaire understanding, and to remove any ambiguity likely when reading the questionnaire by employees especially with the execution. As it has reported previously, decision to couple INRS approach with Karazak and Sigrist methods has been chosen, Fig. 3.

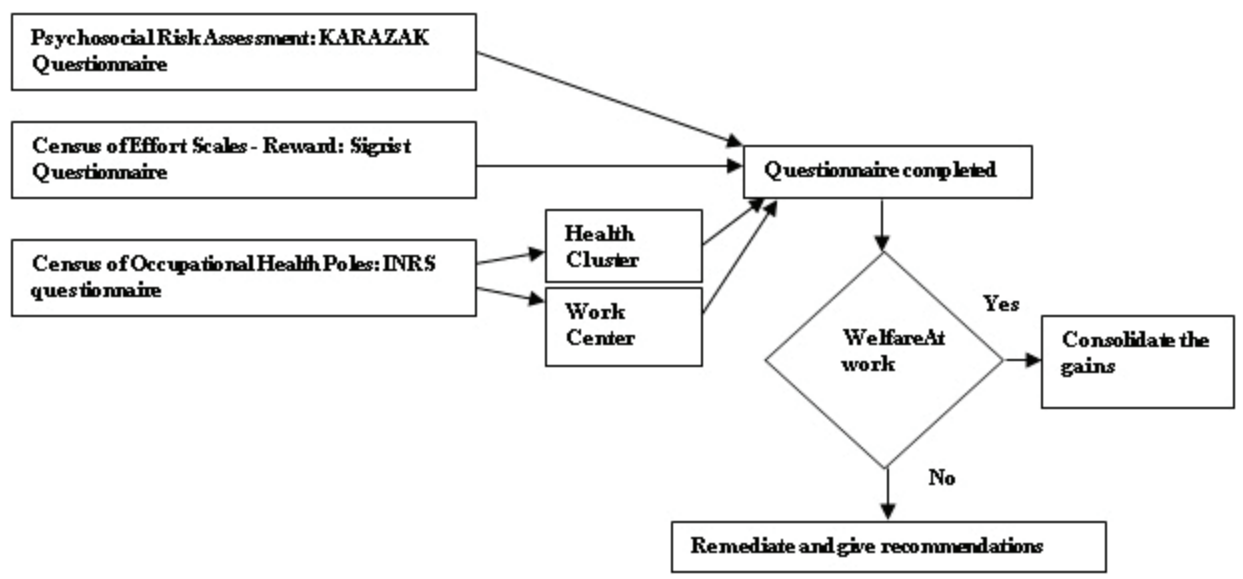

Fig. 3. Proposed work methodology

\subsection{RESULTS AND ANALYZES}

At the beginning, general statement of health in company, as indicated by INRS approach, which breaks down questionnaire in three areas: health pole; work centre and finally social resources centre. For health pole, general feeling in company is shown in Fig. 4.

Initially, employee's general feeling takes an important interest; this component includes five components, results obtained for the three items "overall health, which felt for six months and confidence in the future" present a good overall condition with percentages of $53.48 \%, 60.46 \%$ and $48.06 \%$ respectively. An analysis of socio-professional categories shows that executives are the most satisfied and have a good overall 
feeling $(64.71 \%)$ and the category that suffers the most is workers with only $31.25 \%$ who are not satisfied of their overall condition.

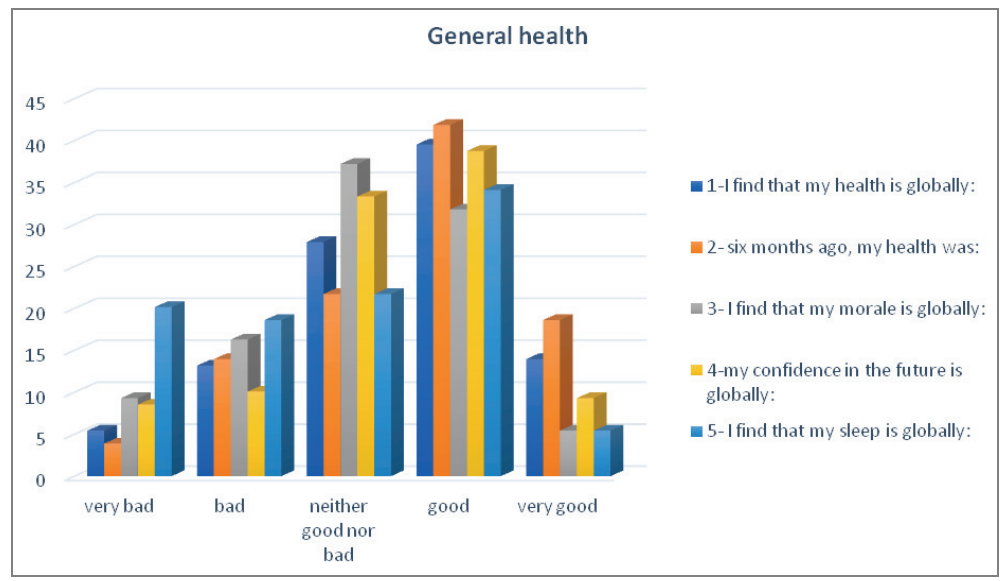

Fig. 4. Generally, felt in the business

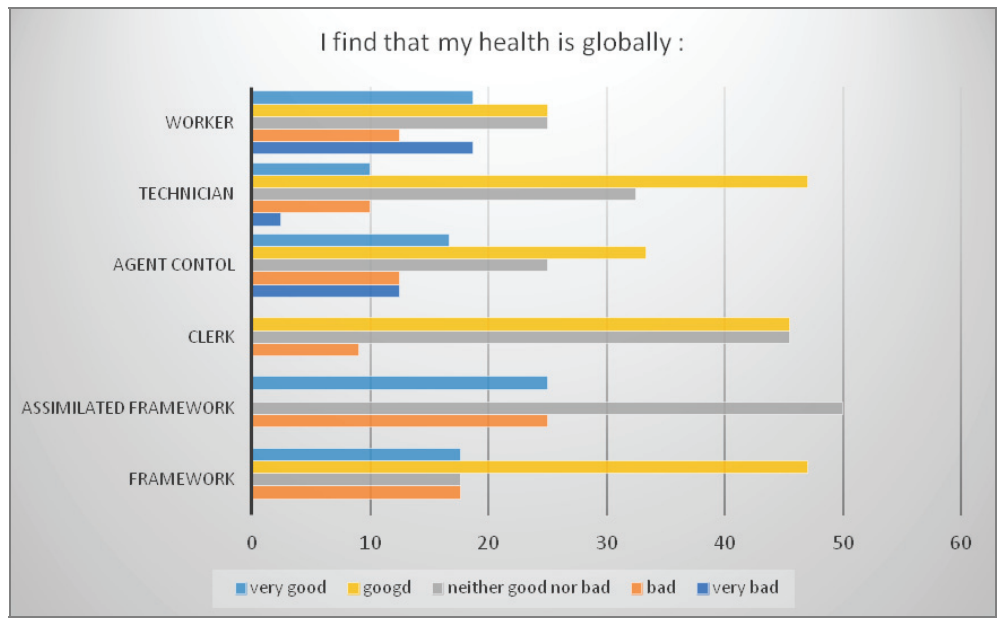

Fig. 5. Overall health for the different professional categories

By doing the same analysis for the different items grouped in the general feeling section, we fond that all the socio-professional categories that have good perceptions, except for the item where the insomnia appears, there is a balance between those who have overall good and bad sleep. The other important point that we studied and which has a direct relation with the health of the employees is that of the musculoskeletal and digestive disorders. 


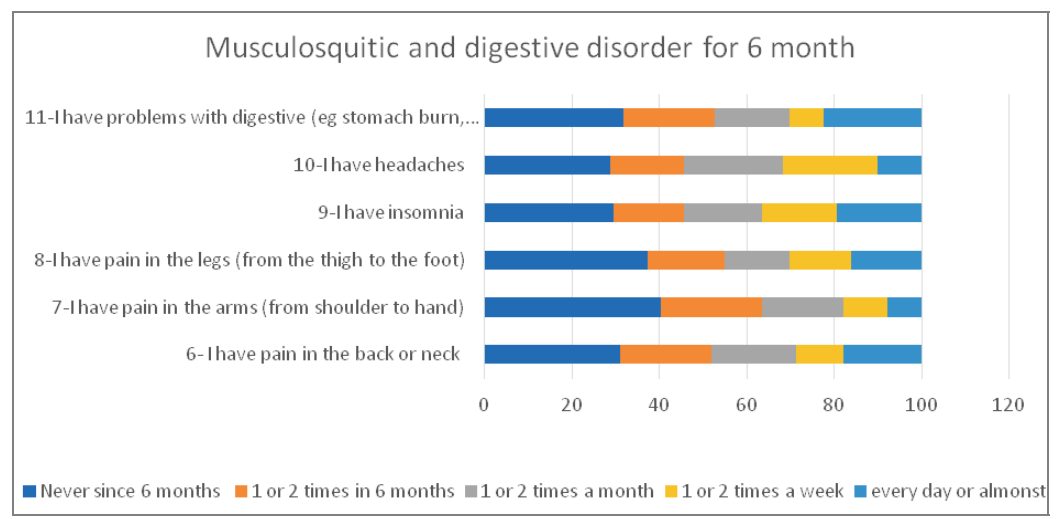

Fig. 6. Musculoskeletal disorders

Musculoskeletal problems, stress, heart disease and respiratory problems infections appear to be the main onset causes of work-related health problems (Drakopoulos et al. 2012).

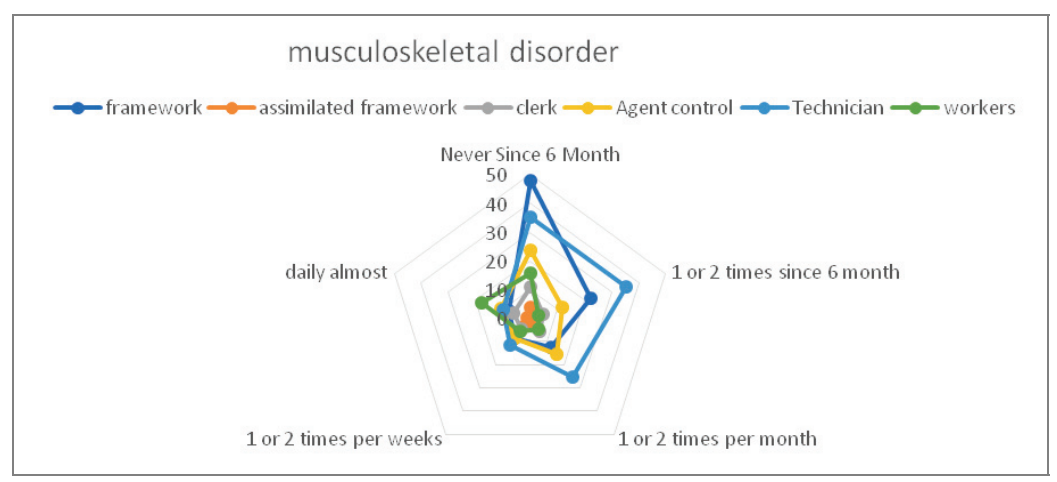

Fig. 7. Musculoskeletal disorders by occupational category

The socio-professional category that at least has musculoskeletal disorder is executives with $48.04 \%$ (never for six months). The category most affected by these disorders is the category of workers with $23.53 \%$ (almost every day and once or twice a week) with technicians $(21.57 \%)$ and masters $(19,61 \%)$. These disorders involve pain in the neck, legs and even the arms. Musculoskeletal disorders are one of the most common categories of occupational diseases and have attracted researchers interest because economic costs of compensation schemes, medical expenses, disability pensions, lost working days and the decline in productivity are considered extremely high (Drakopoulos et al. 2012). 


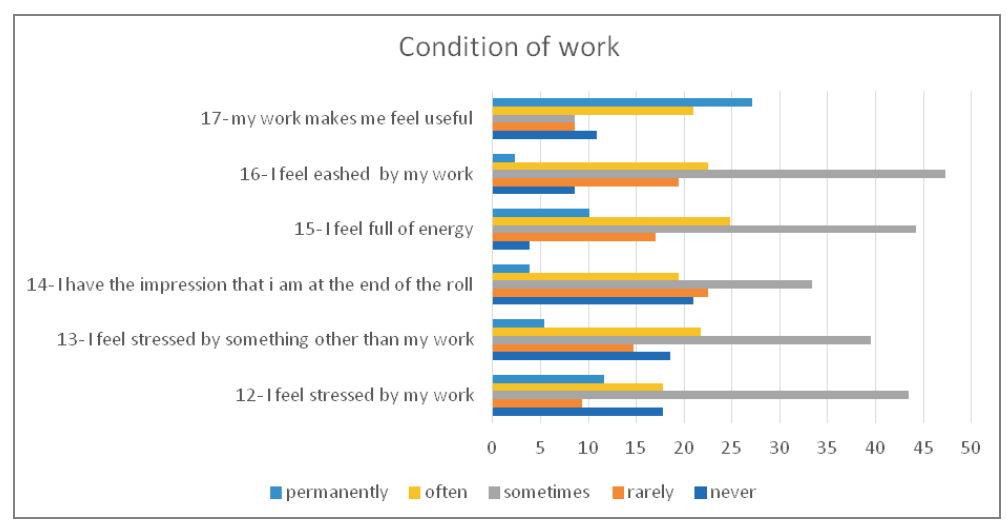

Fig. 8. Condition of work

According to Stavros Drakopoulos et al. (2012) and according to an annual report of the ISS (Drakopoulos et al. 2012), a large number of employees are exposed to undesirable working conditions which can be responsible for work-related stress, burnout and psychosocial diseases. Among factors that characterize well-being is stress at work, which it is our study case. A percentage of $43.41 \%$ of workers consider that they are sometimes stressed by their work and $29.45 \%$ estimates that they are often and permanently. A percentage of $27.13 \%$ of workers are stressed by something other than work, and $39.53 \%$ feel they are stressed sometimes. It is found that socioprofessional categories who feel stressed in their work are workers and supervisors, followed by executives with percentages $43.75 \%, 41.66 \%$ and $32.35 \%$ respectively, against categories that feel they are stressed by something other than work. It is always found workers category with $43.75 \%$ (often) and executives, technicians, masters and clerks with $61.76 \%, 35 \%, 29.16 \%$, and $36.36 \%$ (sometimes). Work-related stress is one aspect of workplace health problems that has been subject of many studies. It is known that stress is strongly influenced by work tasks, organizational environment and workplace conditions (Koukoulaki 2002; Ross, Altmaier 1994; Schultz, Schultz 1998). In theory, "stressors" are more frequently identified (Robert, Grosjean 2006) and are related to: content of the work, work context, individual, by interpersonal relationships. As Baruch Spinoza points out (Spinoza 2013), well-being of collaborator seems to be reflected in field by a better life quality (hygiene), better physiological signals, less illness (psychic, physical, general), and better health for the company (in terms of burnout, absence, turnover, medical visits). The feeling of wellbeing at work is deeply correlated with health, especially when World Health Organization "WHO" in its preamble defines it in 1946: "Health is a complete state of physical, mental and social well-being, and not just an absence of sickness or infirmity".

Secondly, pole of labour centre is studied. Items 24 to 26 refer to (perceived) work demands, distinguishing what is physical, mental and psychological. To ap- 
prehend the spheres which have been just mentioned, the notion of effort to provide seemed relevant to us (Robert, Grosjean, 2006). It is found that all staff believes that their physical abilities and reflections or attention as well as their emotions control are adapted to work demands $(58.91 \%, 54.26 \%$, and $51.16 \%)$. For general aspect of workplace are clerical workers, technicians and workers who do not suit this environment, even for workplace cleanliness but this time in addition to categories mentioned earlier, the agents of mastery are added also to this category. According to SSI's annual reports, a large number of employees are exposed to undesirable working conditions that may be responsible for work-related stress, burnout and psychosocial illnesses (Drakopoulos et al. 2012). For human environment aspect, it is found that there is a certain working atmosphere and trust between colleagues, even relations between hierarchy and subordinate people there is a certain respect between them. But this does not prevent that the same percentages of people do with respect to this human environment. It is workers and office workers who are not satisfied with the atmosphere between colleagues $(31.25 \%$ for $25 \%$ that suits them and $36.36 \%$ for $18.18 \%$ ).

The other aspect that is important for employee's well-being is work organization, in a general way, Fig. 9 shows that all personnel respect criteria that have defined. It has also been seen that percentage of satisfaction for all the criteria is positive except for certain employees who express their dissatisfaction with salary.

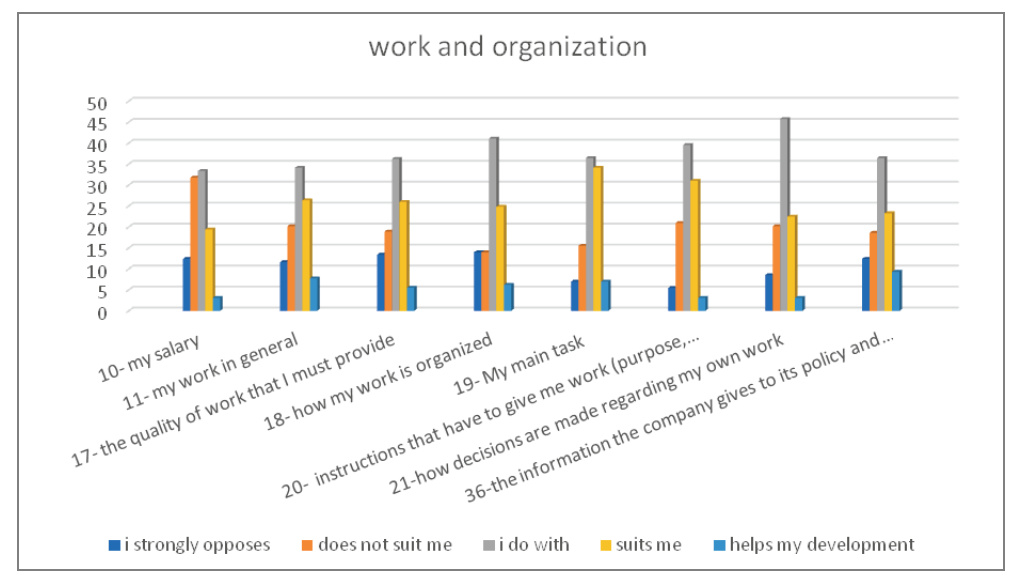

Fig. 9. Work organization

In a detailed way, it is found those workers, assimilated cadres and agents of masters who are not satisfied with their wages. This dissatisfaction of workers and technicians concerns also the way in which their work is organized and instructions that it has been given to them. collaborator well-being seems to be expressed by co-operative behaviours in life in general (city life, associative), by a mutual help in organization 
(colleagues help, cooperation), but also a good social climate (social support network, conflicts) and a greater organizational activity of it (Spinoza 2013). As Stavros Drakopoulos points out (Drakopoulos et al. 2012), interpersonal relations, working conditions, wages and organizational structure also influence job satisfaction.

The last pole of INRS approach will be seen, in this case societal pole. This pole is very important seen that it concerns a concept of the psychology which sends back in a rather obvious way to the resources which an individual mobilizes for facing a situation is the one of coping (Robert, Grosjean 2006). Lazarus, Folkman (Lazarus, Folkman, 1984) define it as "the set of constantly changing cognitive and behavioural efforts deployed to manage specific internal and/or external requirements that are assessed by the individual as consuming or exceeding his or her resources". It noticed that all employees have positive social behaviour, they feel well surrounded and talk with their surroundings about what concerns and share their time with those who are dear to them. For socio-professional categories, all employees of the latter feel well surrounded, which allows them to talk about professional concerns. As noted by Sari Mansour and DianeGabrielle Tremblay (Allen 2012; Mansour, Tremblay 2018), simultaneous management of work and family roles is an issue of concern to employees in most segments of society. In addition, labour and family problems appeared, as there is growing recognition that these challenges have a significant impact on employees well-being (Eby et al. 2010; Mansour, Tremblay 2018); Work-family conflict has therefore become one of main stress sources (Braunstein-Bercovitz 2013). Therefore, policies development and organizational measures that help workers in their work and family responsibilities is crucial for well-being and employees quality life (Mansour, Tremblay 2018).

After having given the results of the INRS approach, using Karazak method, the latter is composed of three axes: decision latitude, mental requirements and social support. For latitude decision, it is found that majority of employees have certain autonomy to make decisions in their work $(42.63 \%)$, a certain freedom in way they perform their tasks $(41.86 \%)$ and they have some influence on way that things work.

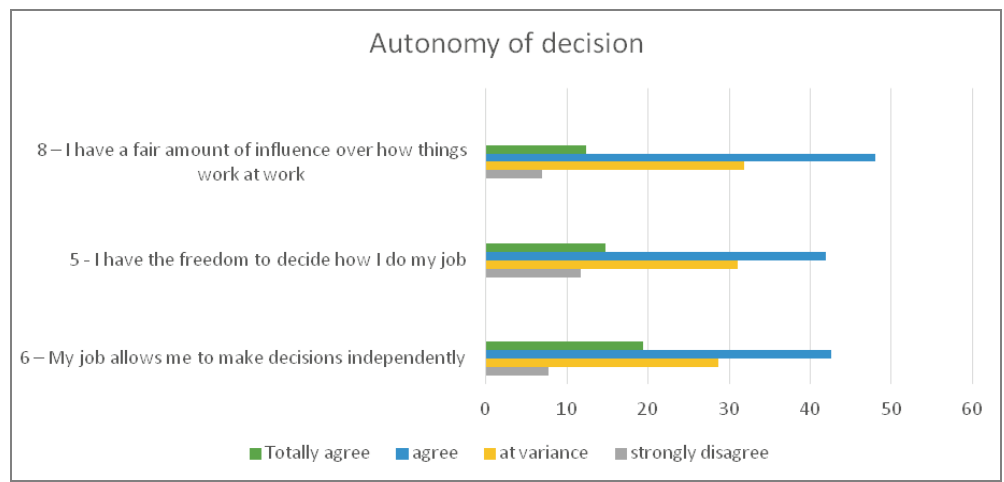

Fig. 10. Autonomy of decision 
For more detail, all socio-professional categories have a freedom to make decisions to accomplish their work in an autonomous way; the percentage is the order of 64, $70 \%$ for executives and $62.5 \%$ for workers. Results for mental requirements, shows that workers have a heavy load, resulting in slowdowns in their tasks $49.61 \%$, intensive work $43.41 \%$, concentration at work $45.73 \%$, and work require to work mentally strong $4341 \%$, however, they have time to complete their tasks and $52.71 \%$ do not receive conflicting demands $45.73 \%$.

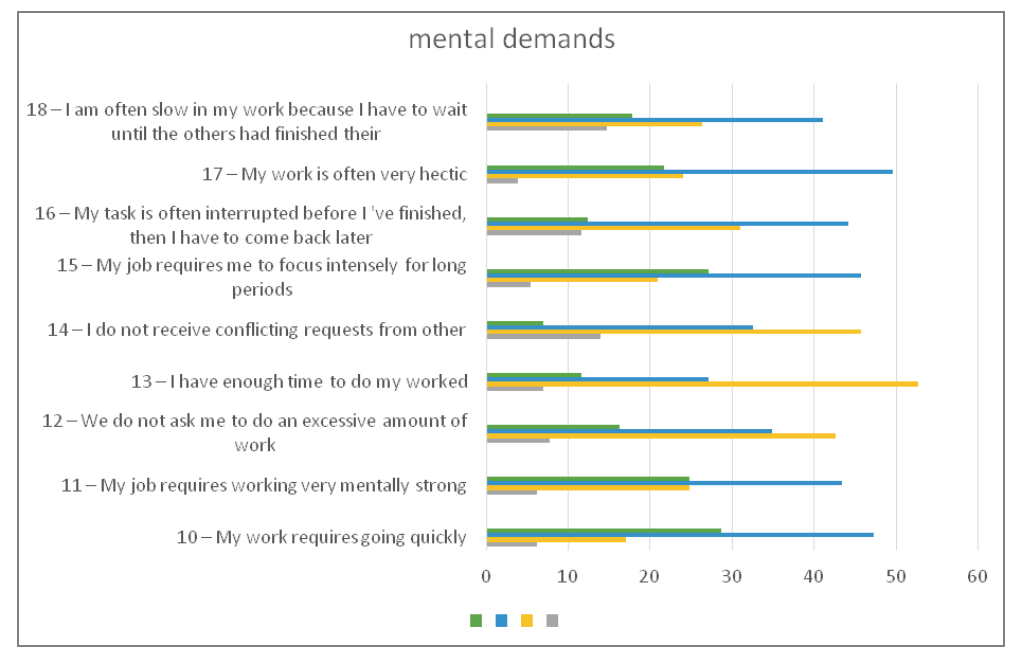

Fig. 11. Mental requirement

Koukoulaki (Koukoulaki 2002) affirms that work-related stress is the most frequently reported work-related health problem for European workers, while work place, time pressure and repetitive tasks are important determinants. Burnout is also caused by stress and is linked to symptoms of emotional exhaustion, depression, irritability, and boredom (Schultz, Schultz 1998). As Stavros Drakopoulos also points out (Drakopoulos et al. 2012), the main consequences of burnout are the loss of interest in the tasks and objectives of work, whereas it is often manifested by various physical and psychosomatic symptoms. In addition, mental health (Dimitropoulos, Filippou 2008). For last part of Karazak's method, social support, which indicates that there is an agreement between co-workers as well as subordinate-hierarchical relationship, and even they feel that their leaders are interested in their well-being.

We have found that all socio-professional categories have a very good relationship between hierarchy and workers, except workers who their leaders do not care about their well being. Following results analysis obtained, it has been noted for our case that the two axes dictated by the method have positive results for well-being (decisional attitude + social support) against mental requirement axis and has a negative 
result for well-being (mental requirement) which can cause stressful situations in work which can harm physical or mental health.

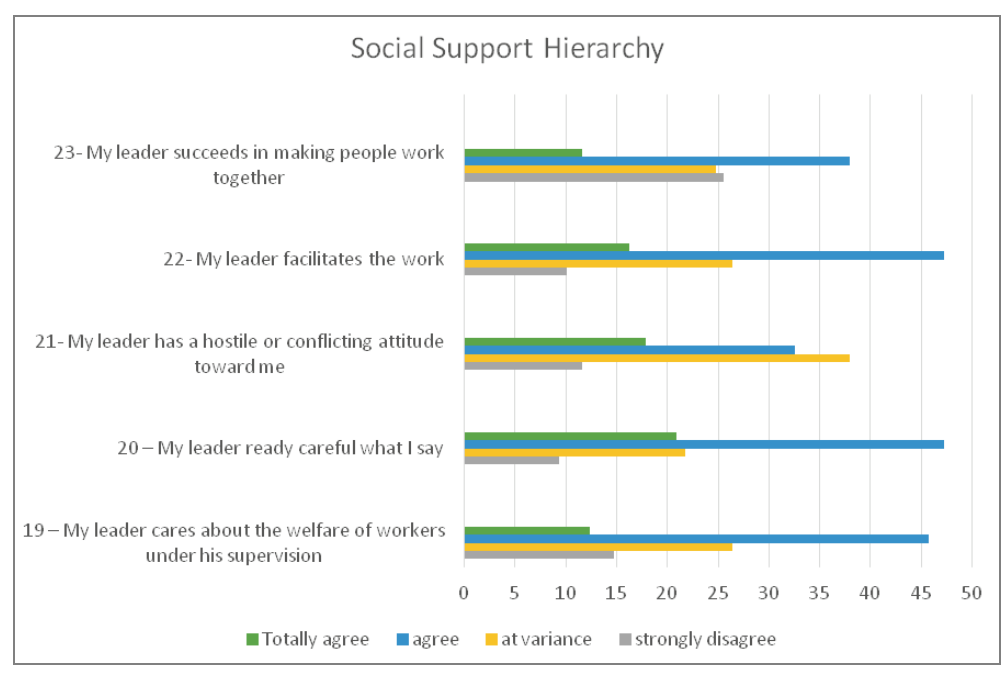

Fig. 12. Social support hierarchy

We have found that all socio-professional categories have a very good relationship between hierarchy and workers, except workers who their leaders do not care about their well being. Following results analysis obtained, it has been noted for our case that the two axes dictated by the method have positive results for well-being (decisional attitude + social support) against mental requirement axis and has a negative result for well-being (mental requirement) which can cause stressful situations in work which can harm physical or mental health.

After that, Karazak method is considered and it is found that it is useful to complete our study with Sigrist method which focuses on effort-reward aspects.

It is remarked that for workers who answered first questions (being constantly pressed for time because of a heavy workload) feels that they are not pressed for time and even though have a strong load they are not disturbed. The Same thing for other questions relating to effort.

As proceeded as before (additions to the modalities) it is found that managers and workers are divided between those who are not pressed by time and those who are, however the other categories are not pressed by time cause a heavy workload.

Markovitsand (Drakopoulos et al. 2012; Markovits et al. 2007), notes that organizational commitment appears to play a role in employee job satisfaction. In fact, when psychological well-being of employees becomes a priority for senior management, workers will ensure that they have sufficient resources at work (Idris, Dollard 2011; Mansour, Tremblay 2018). 


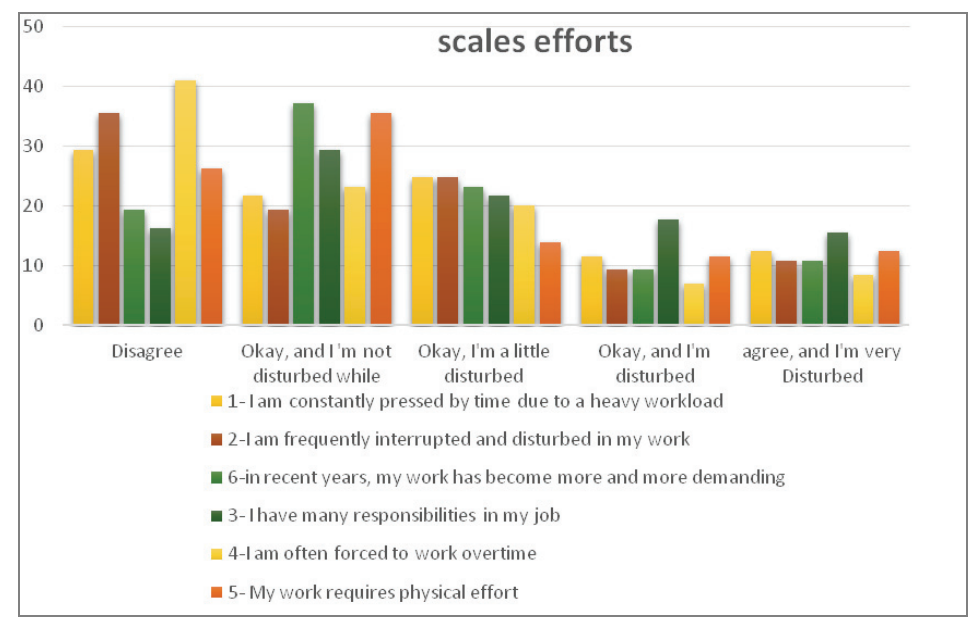

Fig. 13. Scale efforts

The second part of Sigrist method concerns scale of rewards, by analyzing data; it is found that general state of satisfaction along this scale is good.

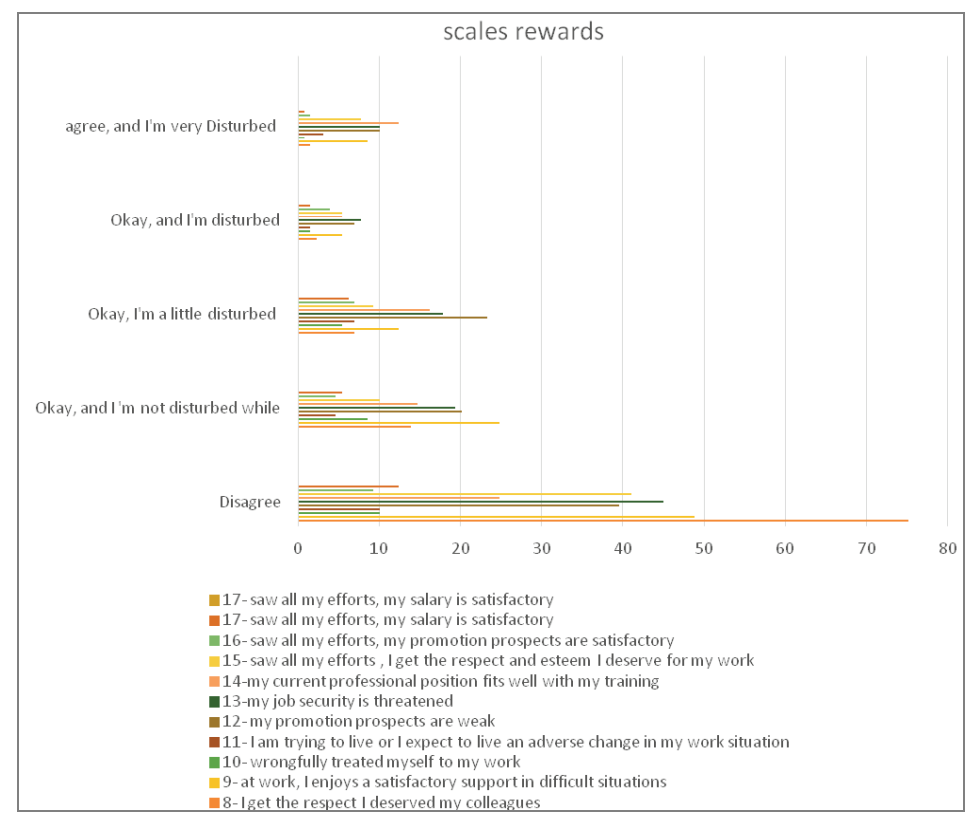

Fig. 14. Scale rewards

For more detailed way, respect for hierarchy taking into consideration the efforts made, has been chosen as example. 


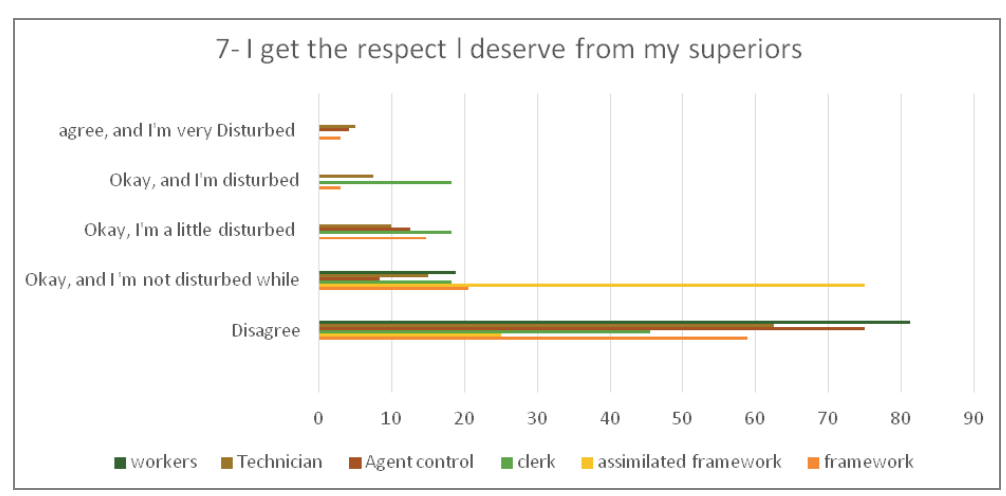

Fig. 15. Example of a Scale awards, by category

As can be seen in figure, all socio-professional categories receive hierarchy respect. As Edmondson (Edmondson 1999) points out, team psychological climate refers to "a belief shared by a team that the team is safe to take interpersonal risks". It is the same observation made by Dollard and Bakker (Dollard, Bakker 2010) that employees who live in a psychologically safe team environment do not engage in risky behaviours.

\section{CONCLUSIONS AND RECOMMENDATIONS}

As this is the first work of its kind in Algeria, this research results are very useful for decision makers: managers and public authorities. In both cases, study will first provide economic evidence to justify an investment policy in the well-being of workers. It will also make it possible to evolve towards construction of more targeted dashboards, developed on scale of studied company or on cement plants scale on one hand and links observed between individual variables and organizational variables of other share. The latter must make it possible to identify some critical indicators to be included in a social dashboard that is sufficiently economic, reproducible from year to year and able to dynamically monitor policy effects to promote well-being in company. Similarly, training managers on these topics is a strategic investment for sustainable performance. From now on, faced with complex organizational systems, taking into account the quality of life at work in managerial practice is very essential. As a recommendation, we advise the managers of the Hamma Bouziane cement plant to:

- Improving working conditions such as workplaces cleanliness, increasing luminosity, reducing noise level and making use of quality personal protective equipment;

- Improving hardware management, as well as increasing level of its technology

- Consolidating relationships between colleagues especially in workers and clerks categories. 
- Studying possibility of increasing salary for Technicians, Masters and Workers categories;

- Reviewing certain manager's behaviours when giving instructions to workers and technicians;

- Reducing disturbances due to frequent stops during tasks execution, to reduce at the same time the contradictory requests and orders;

- Sensitizing the managers to have a little consideration for the workers;

- instilling and promoting a culture of health and safety at work;

- Promoting social dialogue within company between the different actors;

- Integrate prevention from the design of places, equipment, positions and working methods;

- Encourage employee training, awareness and information on health and safety at work.

This standard analysis can be broadened to encompass several sectors of activity given its importance in the management of quality of life at work in managerial practice reflecting the concrete situation in which companies face risks.

\section{ACKNOWLEDGEMENTS}

First of all, I would like to thank the director and the human resources department of the Hamma Bouziane cement factory in Constantine, Algeria, for having welcomed me and providing me with all the means necessary for carrying out this study.

In addition, I would like to thank my supervisor, Prof. R. Chaib, these collaborators Prof. I. Verzea and Prof. A. Bouzaouit, for their availability and assistance throughout the realization of this work.

I would also like to thank especially and to express my gratitude to HSE SERVICE, employees and key stakeholders for carrying out this study. Thank you all.

\section{BIBLIOGRAPHY}

ACHTE I., DELAFLORE J.-L., FABRE C., MAGNY F., SONGEUR C., 2010, How to reconcile performance and well-being at work, MBA HR dissertation, Paris Dauphine University.

ALLEN T.D., 2012, The Work and Family Interface, The Oxford Handbook of Organizational Psychology, Vol. 2.

AUBRY C., 2005, Risk management in French companies: state of play and the emergence of a cognitive and organizational approach, Accounting and Knowledge.

BRAUNSTEIN-BERCOVITZ H., 2013, A multidimensional mediating model of perceived resource gain, work-family conflict sources, and burnout, International Journal of Stress Management, 20 (2), p. 95.

CHAIB R., 2016, For sustainable development in OHS in companies, European University Publishing.

DE L'EUROPE C., 2008, Well-being for all: concepts and tools of social cohesion, Council of Europe Publishing.

DELOBBE N., DE HOE R., 2012, Is workplace well-being a factor of organizational performance? A multi-level study in the Belgian food distribution sector, Leuven: University of Leuven.

DELOCHE F., tuesday 19 march 2013 - 9h - 17h30, What is well-being through work? Well-being by work: a utopia? How to reconcile performance and pleasure around our ways of working together?

DIMITROPOULOS C., FILIPPOU N., 2008, Professional burnout in health professionals, Archives of Hellenic Medicine, 25 (5), pp. 624-647. 
DOCUMENT L. c. d. THE PROCESS OF MANUFACTURING CEMENT.

DOLLARD M.F., BAKKER A.B., 2010, Psychosocial safety climate as a precursor to conducive work environments, psychological health problems, and employee engagement, Journal of Occupational and Organizational Psychology, 83 (3), pp. 579-599.

DRAKOPOULOS S., ECONOMOU A., GRIMANI K., 2012, A survey of safety and health at work in Greece, International Journal of Workplace Health Management, 5 (1), pp. 56-70.

EBY L.T., MAHER C.P., BUTTS M.M., 2010, The intersection of work and family life: The role of affect, Annual Review of Psychology, 61, pp. 599-622.

EDMONDSON A., 1999, Psychological safety and learning behavior in work teams, Administrative Science Quarterly, 44 (2), pp. 350-383.

IDRIS M.A., DOLLARD M.F., 2011, Psychosocial safety climate, work conditions, and emotions in the workplace: A Malaysian population-based work stress study, International Journal of Stress Management, 18 (4), p. 324.

KARASEK R., 1990, Healthy work. Stress, productivity, and the reconstruction of working life.

KOUKOULAKI T., 2002, Stress prevention in Europe: review of trade union activities - Obstacles and future strategies, TUTB Newsletter, 19 (20), pp. 4-9.

LACHMANN H., LAROSE C., PÉNICAUD M., 2010, Well-being and efficiency at work. Ten proposals to improve psychological health at work, Report to the Prime Minister.

LAZARUS R., FOLKMAN S., 1984, Stress, coping and appraisal, Springer, New York.

MANSOUR S., TREMBLAY D.-G., 2018, Psychosocial safety climate as resource passageways to alleviate work-family conflict: A study in the health sector in Quebec, Personnel Review, 47 (2), pp. 474-493.

MARKOVITS Y., DAVIS A.J., VAN DICK R., 2007, Organizational commitment profiles and job satisfaction among Greek private and public sector employees, International Journal of Cross Cultural Management, 7 (1), pp. 77-99.

MÉDÉC M., 2013, Health and wellness in business, Key Figures 2013.

MÉDÉC M., 2014, Employee Health and Well-Being Report, Business Performance Key Figures 2014. President of the International Social Observatory (OSI).

MILlOT M., ROULLEAU J.-P., 2013, State-of-the-art companies, Maxima Laurent du Mesnil Editor.

NIEDHAMMER I., SIEGRIST J., LANDRE M.-F., GOLDBERG M., LECLERC A., 2000, Study of the psychometric qualities of the French version of the Effort. Reward Imbalance model, Journal of Epidemiology and Public Health, 48 (5), pp. 419-438.

PHILLIPPE N., JACQUES H., YANN T., 2014, Bien être au travail et performance économique, le sens de la reconnaissance au cœur de la performance, DIRECCTE Rhône-Alpes Direction réginale des entreprises, de la Concurrence, de la Consommation, du Travail et de l'Emploi.

RACHID C., MOHAMED B., 2016, For a Sustainable Development in Occupational Safety and Health, Occupational Medicine and Health Affairs.

RICHER M., 2013, "Well-being and efficiency": for a quality of life policy at work, Terra Nova, Note 1/22, March 2013.

ROBERT N., GROSJEAN V., 2006, Development of a well-being questionnaire. For a reinforced dialogue on labor-human resources, National Institute of Research and Security (INRS).

ROSS R.R., ALTMAIER E.M., 1994, Intervention in occupational stress: A handbook of counselling for stress at work, Sage.

SCHULTZ D., SCHULTZ S.E., 1998, Psychology and Work Today, An Introduction to Industrial and Organizational Psychology (8th).

SIEGRIST J., STARKE D., CHANDOLA T., GODIN I., MARMOT M., NIEDHAMMER I., PETER R., 2004, The measurement of effort-reward imbalance at work: European comparisons, Social Science and Medicine, 58 (8), pp. 1483-1499.

SPINOZA B., 2013, Well-being at work, an objective in itself and a vector of economic performance, Think-tank of well-being edition.

STIGLITZ J.E., 2002, Employment, social justice and well-being, International Labor Review, 141 (1-2), pp. 9-31. 